absorption maxima. The above xanthophylls are present in the petals in the ester form.

We hope to publish shortly a detailed account of this investigation elsewhere.

\section{Chemistry Department, University College, Cork. \\ Dec. 18}

${ }^{2}$ Biochem. J., 28, 1715 (1934).

'Biochem. J., 25, 1699 (1931)

- Flora, 107, N.S. 7, 371-342.

- Ber., 64, 332 (1931).
W. F. O'CONNOR.
P. J. Drumm.

Although creatine has no influence, creatinine exerts powerful protection against the oxidation of the vitamin. Similar results were obtained when the oxidation of the vitamin was followed by titration with the indophenol dye.

In addition to glutathione and other thiol compounds which are known to exert similar protective action against the oxidation of vitamin $\mathrm{C}$, the presence of purines and creatinine in the body may insure the existence of reduced vitamin $\mathrm{C}$ or prevent the oxidation of the vitamin by $\mathrm{Cu}^{*}$.

Further work on the mechanism of inhibition of the oxidation by the purine derivatives is in progress. Full detaiks of the work will be published elsewhere. K. V. GIRI.

Andhra University, Waltair, South India.

\title{
Influence of Purines, Creatinine and Creatine on the Oxidation of Vitamin C
}

IN a recent communication ${ }^{1}$ evidence was presented to show the co-existence of oxidizing and protective mechanisms for vitamin $\mathrm{C}$ in plant tissues. While investigating the effect of various biologically important substances of very diverse nature, on the oxidation of vitamin $\mathrm{C}$ in presence and absence of $\mathrm{Cu}$ ", we have made some observations regarding the influence of purine derivatives, creatinine and creatine on the oxidation, which offers useful information regarding the nature of the protective mechanism existing in plant and animal tissues.

The oxidation of vitamin $\mathrm{C}$ was studied at $p \mathrm{H} \cdot \mathbf{7} \cdot 2$ in presence of $\mathrm{Cu}$ " in the Warburg manometers at $30^{\circ}$. The oxygen uptake was measured in the presence and absence of the substances under investigation, and the results are presented in the following table.

Ascorbic acid, $2 \mathrm{mgm}$; $\mathrm{Cu} \cdot \cdot 0.71 \mu \mathrm{gm}$. ; total volume 3 c.c. Air, $30^{\circ}$.

\begin{tabular}{|c|c|c|c|c|c|}
\hline & \multirow{3}{*}{ Substance } & \multirow{3}{*}{$\begin{array}{l}\text { Concentra- } \\
\text { tion } M\end{array}$} & \multicolumn{2}{|c|}{$\mu \mathrm{O}_{2}$ uptake } \\
\hline & & & & \multicolumn{2}{|c|}{ Time in minutes } \\
\hline & & & & 15 & 30 \\
\hline Vitami & $\mathrm{Cu} \cdots+$ & None & - & 66 & 130 \\
\hline ," & $" \quad+$ & xanthine & 0.00017 & 0 & 0 \\
\hline ," & + & uric acid & $0 \cdot 00015$ & 0 & 0 \\
\hline , & + & theophylline & $0 \cdot 00014$ & 13 & 17 \\
\hline ", & ", & theobromine & $0 \cdot 0007$ & 65 & 120 \\
\hline , & + & caffeine & $0 \cdot 00064$ & 62 & 121 \\
\hline , & ," & creatinine & $0 \cdot 0011$ & 5 & 10 \\
\hline , & ", & creatine & 0.00095 & 62 & 130 \\
\hline
\end{tabular}

The results show that the oxidation of vitamin $\mathrm{C}$ by $\mathrm{Cu} . \cdot$ is completely inhibited by the purines-.xanthine, uric acid and theophylline, in a final concentration of $0 \cdot 00014-0.00017 M$., while caffeine and theobromine even at higher concentrations have no influence on the oxidation. The imino group appears to exert influence on the inhibiting action of the purines, as only those of which the imino group is free (for example, xanthine, uric acid and theophylline) inhibit the oxidation, while those whose imino groups are methylated show no inhibitory effect (for example, caffeine). Further, the presence of methyl group in position 7 completely prevents the inhibiting action of the purines, although the other imino group is free (for example, theobromine). Thus the imino group in position 7 of the purine derivatives appears to exert a decisive influence on the oxidation of the vitamin.

An interesting difference between creatinine and creatine, the two important constituents of the muscle, is revealed by their influence on vitamin $\mathrm{C}$ oxidation.

Andhra Medical College,

Vizagapatam, India.

Nov. 1 .

1 Giri, K. V., and Krishnamurthy, P. V., Nature, 146, 99 (1940).

\section{Hydration of Carbon Dioxide and the Stability of Hypochlorite Aerosols}

Powell $^{1}$ and Baker and Finn ${ }^{2}$ have considered the effect of the slow hydrolysis of carbon dioxide on the stability of hypochlorite aerosols: The work of $\mathrm{McBain}^{3}$ is quoted when in fact much subsequent work of greater accuracy has appeared; a summary of this work has recently been published ${ }^{4}$. In a series of experiments involving the accurate use of a difficult technique, Faurholt ${ }^{5}$ measured the actual magnitudes of the rate constants for the reactions of carbon dioxide with water and hydroxide ion. The reaction with hydroxide ion is much the more rapid. The velocity of hydration in a given aqueous solution is thus a function of the $p \mathrm{H}$, and can be calculated by summing the contributions to the rate by water molecules and hydroxide ions. In addition, the reaction is catalysed by bases and will be accelerated by anions of weak acids ${ }^{\boldsymbol{c}}$.

From these data the velocity of "changes occurring between the collision of carbon dioxide molecules in the air with droplets of the aerosol and the appearance of the corresponding hydrogen ion" can be easily estimated. It is noted ${ }^{2}$ that the aerosols are decreasingly effective in acid, neutral, and alkaline solution. In alkaline solution carbonic acid would be produced from carbon dioxide more quickly than in acid or neutral solution; liberation of $\mathrm{HOCl}$ would occur more rapidly and loss of $\mathrm{HOCl}$ by evaporation would be more serious.

Research Laboratories, Imperial Chemical Industries

(Dyestuffs), Ltd.,

Manchester. Dec. 14.

1 Powell, Nature, 146, 401 (1940).

Baker and Finn, NATURE, 146, 747 (1940).

'McBain, J. Chem. Soc., 101, 814 (1912).

- Olson and Youle, J. Amer. Chem. Soc., 62, 1027 (1940).

- Faurholt, J. chim. phys., 21, 400 (1924).

- Roughton and Booth, Biochem. J., 32, 2049 (1938). 